\title{
TRAVESSIAS E ITINERÁRIOS QUE FAZEM O "SER" RIBEIRINHO SERTANEJO NO BAIXO RIO SÃO FRANCISCO
}

Cícero Bezerra da Silva ${ }^{1}$ Maria Augusta Mundim Vargas ${ }^{2}$

Resumo: $O$ artigo apresenta os sentidos de Ser Ribeirinho Sertanejo. A construção dessas significações decorreu da convivialidade expressa no relacionamento com o rio e com o sertão. Apresentamos como referencial de investigação empírica o baixo curso do rio São Francisco inserido no domínio das terras semiáridas, entre os estados de Alagoas e Sergipe. Neste processo investigativo, recorremos à entrevista semiestruturada, buscando envolver as terras, as águas e as gentes que caracterizam e dão singularidade a um ambiente socioeconômico, cultural e identitário marcado pela profunda interação do homem com a natureza. Essa interação se dá pelas práticas cotidianas e pelas relações de pertencimento que caracterizam os sentidos de ser-no-mundo e de ser ribeirinho sertanejo.

Palavras-chave: Convivialidade. Lugar-território. Ser-no-mundo. Ribeirinho Sertanejo.

\section{CROSSINGS AND ITINERARIES THAT MAKE THE "BEING" RIBEIRINHO SERTANEJO IN THE LOW RIVER SÃO FRANCISCO}

Abstract: The article presents the meanings of Ser Ribeiro Sertanejo. This construction is due to the conviviality expressed in the relationship with the river and the backlands. We present as an empirical research reference the low course of the São Francisco River in the semiarid lands domain, between the states of Alagoas and Sergipe. In this investigative process, we used the semi-structured interview, seeking to involve the lands, waters and people that characterize and give uniqueness to a socioeconomic, cultural and identity environment marked by the profound interaction of man and nature. This interaction takes place through practices and the relations of belonging that characterize the meanings of being-inthe-world and being a sertanejo riverine.

Keywords: Conviviality. Place-territory. Be-in-the-world. Ribeirinho sertanejo.

\section{CRUCES E ITINERARIOS QUE HACEN EL "SER" RIBEIRINHO SERTANEJO EN EL BAJO RÍO SÃO FRANCISCO}

Resumen: El artículo presenta los sentidos de Ser Ribeirinho Sertanejo. La construcción de esas significaciones se derivó de la convivencia expresada en la relación con el río y con el sertón. Presentamos como referencial de investigación empírica el bajo curso del río São Francisco insertado en el dominio de las tierras semiáridas, entre los estados de Alagoas y Sergipe. En este proceso investigativo, recurrimos a la entrevista semiestructurada, buscando envolver las tierras, las aguas

\footnotetext{
${ }^{1}$ Universidade Federal de Sergipe, Programa de Pós-graduação em Geografia (PPGEO/UFS), São Cristóvão - SE, Brasil, cicerogeografia016@gmail.com, https://orcid.org/ 0000-0001-6013-4797.

2 Universidade Federal de Sergipe, Programa de Pós-graduação em Geografia (PPGEO/UFS), São Cristóvão - SE, Brasil, guta98@gmail.com.br, https://orcid.org/ 0000-0002-0815-6187.
} 
y las gentes que caracterizan y dan singularidad a un ambiente socioeconómico, cultural e identitario marcado por la profunda interacción del hombre con la naturaleza. Esta interacción se da por las prácticas cotidianas y por las relaciones de pertenencia que caracterizan los sentidos de ser-en-mundo y de ser ribeirinho sertanejo.

Palabras clave: Convivencia. Coloca-territorio. Estar en el mundo. Riberinho sertanejo.

\section{Introdução}

$\mathrm{Na}$ composição deste estudo, partimos do entendimento de que a realidade geográfica do rio São Francisco se apresenta de forma complexa e dinâmica. Ela envolve os aspectos físicos, mas também agrega as singularidades socioeconômicas, culturais e identitárias que caracterizam processos históricos de mudanças e permanências, embrionariamente ligados às vivências e aos significados que os diversos grupos sociais atribuem ao ambiente.

Pensar o rio São Francisco implica considerar os povos que historicamente se estabeleceram em suas margens, ocupando as terras de beira-rio e aquelas mais distantes. Tendo o ambiente natural como referência, esses povos estabeleceram distintos vínculos territoriais e identitários em toda a extensão de seus mais de 2700 $\mathrm{km}$, entremeados e intercalados de lagoas, cerrados, matas, caatingas, cachoeiras, corredeiras e ilhas.

Por essa abordagem, torna-se inexequível pensar em uma unicidade de cultura e de identidade no lugar-território sanfranciscano conforme abordado por Almeida (2008), Brandão (2013), Souza e Brandão (2012), Souza (2012) e outros. O objeto deste estudo encerra uma multiplicidade de culturas e de identidades ressignificadas no tempo-espaço e afeiçoadas ora pelas águas, ora pelas terras que aqui propomos chamá-las de "sertão".

O sertão que apresentamos refere-se às terras e às águas do domínio semiárido e das caatingas, àquele inserido nas depressões interplanálticas do vale do rio São Francisco. Nesse contexto, consideramos a amplitude do termo "sertão", tantas vezes aplicado a fim de representar distintos tipos de territórios, identidades, culturas e lugares. Para isso, recorremos às abordagens dos autores acima referenciados, bem como às contribuições de Rosa (1986), Ab' Saber (1999), Vargas (1999; 2003), Moraes (2002-2003), Mendes e Almeida (2009) e Almeida (2018; 2005). Para esses, os sertões são múltiplos, plurais, diversos, tanto quanto 
são os sertanejos. Esses autores apresentam-se como motivadores de novas buscas, quiçá, de descobertas.

A construção e a ressignificação das identidades sanfranciscanas, enquanto produto das relações estabelecidas com o meio ambiente e social, abriu-nos os caminhos para pensar os vínculos afetivos e de pertencimento, um tipo de convivialidade, ou seja, "uma espécie de relação social, política e simbólica que liga o homem a sua terra e, simultaneamente, estabelece sua identidade cultural". (ALMEIDA, 2018, p. 298-299).

Assim, apresentamos a identidade como produto das vivências e das territorialidades que cotidianamente se estabelecem nas águas e nas margens do rio e dos afluentes. Essas territorialidades são portadoras de elementos materiais - o rio, a terra, o domínio fitogeográfico - mas também de elementos simbólicos - mitos, lendas, relações topofílicas e/ou topofóbicas e de pertencimento - e são o reflexo das representações inerentes à subjetividade dos indivíduos em suas mais diversas tipologias identitárias.

O rio São Francisco, pensado em sua totalidade, no conjunto da bacia hidrográfica (Figura 1), abrange $7,5 \%$ do território brasileiro, cerca de $639.219 \mathrm{~km}^{2}$, banhando o território de 504 municípios que se distribuem entre as regiões CentroOeste, Sudeste e Nordeste do país. O rio Principal, o São Francisco, nasce no estado de Minas Gerais e flui na direção sul-norte, com confluência no oceano Atlântico entre os estados de Alagoas e Sergipe.

Segundo o Comitê da Bacia Hidrográfica do Rio São Francisco (2018), a bacia hidrográfica está compreendida entre sete unidades da federação: Bahia, 48,2\%; Minas Gerais, 36,8\%; Pernambuco, 10,9\%; Alagoas, 2,2\%; Sergipe 1,2\%; Goiás, 0,5 e o Distrito Federal, 0,2\%. E, para fins de planejamento, é subdividida em quatro sub-regiões hidrográficas: Alto São Francisco, $111.804 \mathrm{~km}^{2}$; Médio, $339.763 \mathrm{~km}^{2}$; Submédio, $155.637 \mathrm{~km}^{2}$ e baixo rio São Francisco, $32.013 \mathrm{~km}^{2}$.

O alto curso constitui a área de nascentes na Serra da Canastra/MG e se alonga até a cidade de Pirapora, também em Minas Gerais. O médio curso se estende desta cidade até Remanso, no estado da Bahia, apresentando como área limítrofe o lago de Sobradinho; o submédio curso do rio São Francisco compreende o recorte que se entremeia de remanso até Paulo Afonso/BA e, por fim, o baixo curso, que se alonga de Paulo Afonso à foz, na divisa dos estados de Alagoas e Sergipe (AGUIAR NETTO, et al, 2011; CBHRSF, 2018). 
Para Pierson (1972, p. 37), a subdivisão do rio São Francisco em quatro partes pode ser caracteriza como sendo "1) a faixa das cabeceiras; 2) o verdadeiro coração do São Francisco; 3) a faixa das corredeiras e cataratas; e 4) a faixa virtualmente ao nível do mar". Essa regionalização, assim, leva em consideração as características da base física do rio, a localização dos principais afluentes e o uso que o homem o atribui ao ambiente (PIERSON, 1972).

\section{Figura 1: Bacia Hidrográfica do Rio São Francisco}

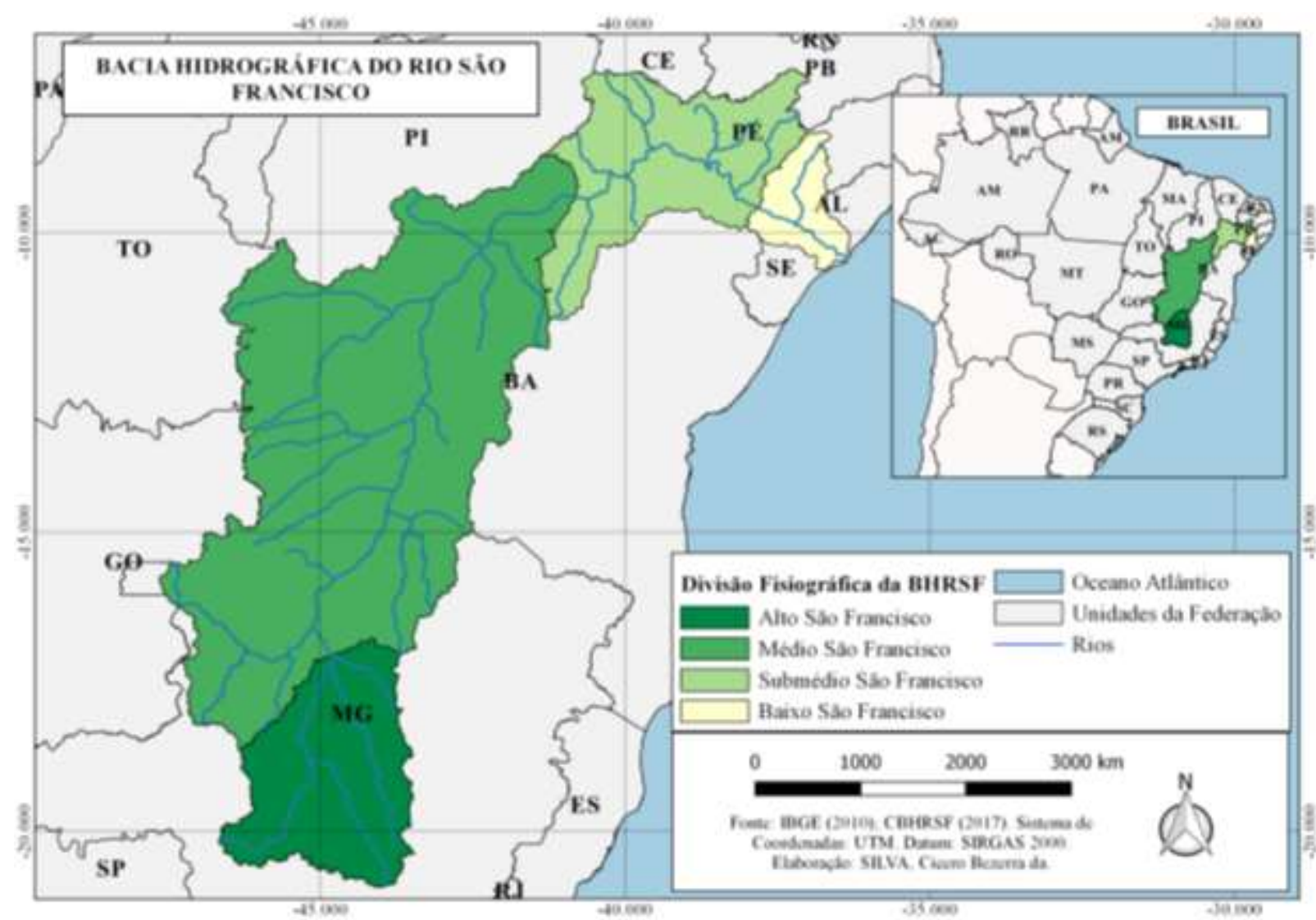

Fonte: CBHRS (2018).

Isso posto, essas características contribuem para a denominação atribuída ao rio pelas políticas de governo da primeira metade do século $\mathrm{XX}$, a saber, "Rio da Integração Nacional", por este constituir um canal de ligação entre as diferentes regiões do país. Para tanto, como contraponto, entendemos pela natureza e pela cultura dos povos que a espacialidade do "Rio da Integração Nacional" conforma um mosaico de lugares de vida, onde as necessidades básicas, como moradia, alimentação, transporte, lazer, etc. são satisfeitas. Por sua cultura e geograficidade singular, o rio São Francisco tornou-se um lugar de lugares diversos, um mundo de significados, um espaço vivido.

O lugar, nas tessituras apresentadas por Tuan (2013, p. 28), constitui "pequenos mundos" e tem sua construção moldada pelas vivências e experiências 
no espaço. O lugar é, portanto, o espaço experienciado, onde nossas vidas adquirem sentido. O mundo, tal qual o conhecemos, é apresentado por MerleauPonty (1996) como o lugar de vida e extensão da existência humana.

Com essa compreensão, assinalamos algumas considerações sobre a natureza e a cultura como elementos constitutivos de referência material e simbólica e que caracterizam o rio como lugar de identidade, marco referencial de experiências cotidianas, enfim, que exprime a existência do ribeirinho sertanejo.

Quanto à referência empírica da análise, para fins de representação, buscamos nos ater ao recorte territorial inserido no domínio das terras semiáridas localizadas à jusante do lago da usina hidroelétrica de Xingó, entre os estados de Alagoas e Sergipe. A apreensão dos sujeitos da pesquisa se deu, de modo mais específico, nos povoados, sedes municipais e localidades inseridas nas terras de rio e beira-rio, em ambas as unidades da federação. Na margem alagoana, as visitas se deram nos territórios dos municípios de Piranhas, Pão de Açúcar, Belo Monte e Traipu. Em Sergipe, detemo-nos as localidades inseridas nos municípios de Canindé de São Francisco, Poço Redondo, Porto da Folha, Gararu e Nossa Senhora de Lourdes.

A justificativa para desenvolver a pesquisa entre as duas margens do rio São Francisco parte do entendimento de que não existe, sob a abordagem humanista e cultural, uma região ribeirinha alagoana ou sergipana, o que ocorre é uma região ribeirinha sanfranciscana, caracterizada por territorialidades diversas que se vinculam pelo rio e pelo sertão semiárido, e isso ocorre de forma independente aos limites cartesianos politicamente estabelecidos.

\section{Do método e dos procedimentos}

Aportados na pesquisa qualitativa, orientada pelo método fenomenológico, buscamos apreender os aspectos constitutivos do semiárido do baixo rio São Francisco e os sentidos de ser ribeirinho sertanejo pela compreensão de quem vive entre as margens do rio e atua sobre ele em um processo interativo e dinâmico. Pela fenomenologia, enfatizaremos as percepções, as territorialidades e as experiências cotidianas que caracterizam e dão singularidade aos lugares e aos sujeitos que margeiam e ocupam rio e sertão.

Ao buscar aporte na fenomenologia, nossa preocupação consiste em ir além daquilo que já está posto, visível e dado como acabado. Da aparência do fenômeno buscamos adentrar nas essências da vida ribeirinha. Da "contemplação" da 
paisagem, buscamos os "sedimentos" como elementos constitutivos da vida presente, enquanto revelação das identidades, das lembranças e do enraizamento.

Ao desvelar o mundo percebido, Merleau-Ponty (1996, p. 279) nos chama atenção para o fato de que "o pensamento objetivo ignora o sujeito da percepção. Isso ocorre porque ele se dá ao mundo inteiramente pronto, como meio de todo acontecimento possível, e trata a percepção como um desses acontecimentos". Todavia, o rebatimento a esse modelo de pensamento pode ser dado pela compreensão de que "a percepção é um ato, um produto da história e do tempo" e não apenas uma casualidade observada.

Assim, “a percepção atesta e renova em nós uma 'pré-história'. [...] não haveria o presente, quer dizer, o sensível com a sua espessura e sua riqueza inesgotável, se a percepção [...] não conservasse um passado em sua profundida presente". (MERLEAU-PONTY, 1996, p. 322). A percepção, para Oliveira (2002, p.191) consiste em um conjunto de sistemas, nos quais é possível caracterizar as estruturas, não por decisões arbitrárias, mas procurando traduzir passo-a-passo em expressões precisas, as condutas dos sujeitos, das pessoas".

Por esse balizamento, assumimos a percepção e as relações simbólicas e materiais como um conjunto indissociável da relação homem-natureza. Neste contexto, coadunamos com Nogueira (2005, p. 04) ao considerar que "a perspectiva fenomenológica na geografia deixa de priorizar a descrição do mundo físico, para descrever o mundo vivido, onde o físico/humano são elementos percebidos e interpretados pelos diversos sujeitos que os experienciam". Por este motivo nos aportamos das bases físicos como elemento condutor das percepções frente aos modos de vida que se adensam no vale do rio São Francisco, já que a fenomenologia é, também, "um relato do espaço, do tempo, do mundo vivido". (MERLEAU-PONTY, 1996, p. 05).

Essa forma de ler a realidade geográfica tem nos permitido entender o lugar sanfranciscano como um fenômeno experienciado pelos sujeitos que nele vivem e atuam e, desse modo, aproximamo-nos da geograficidade apresentada por Dardel (2015, p. 42) ao referir-se às "várias maneiras pelas quais sentimos e conhecemos o ambiente em todas as suas formas, constituindo a relação visceral que o homem mantem com a terra". Como categoria geográfica de análise, propomos uma aproximação entre lugar e território e, para isso, levamos em consideração o fato de estas se entrecruzarem, à medida que trataremos das relações de pertencimento, dos significados e das experiências unívocas à identidade. 
A diversidade das formas de relacionamento com o lugar e com o território, expressas pelas relações de pertencimento, pela subjetividade e pelas representações de poder, faz-nos concordar com Souza (2013, p. 121) ao considerar que "na prática, lugares são, menos ou mais claramente, e menos ou mais fortemente, quase sempre territórios". E acrescenta:

Dizer que, em se tratando do conceito de lugar, não é mais a dimensão do poder que é aquela mais imediatamente perceptível, mas sim a dimensão cultural-simbólica, não significa, porém, de jeito nenhum, sugerir que a dimensão do poder não deva ser levada em conta. Pensar assim seria cometer um rematado disparate. (SOUZA, 2013, p. 115-116).

Haesbaert (2016, p. 27) expressa que há uma "constelação geográfica de conceitos" no entorno da categoria-mestra que é o espaço. Pelo conceito de território, enfatizamos uma "relação entre espaço e poder, a dimensão política do espaço" e, pelo conceito de lugar, destacamos a "dimensão cultural-simbólica, o vivido, onde a construção identitária é um elemento fundamental".

Nesse alinhamento, Almeida (2005, p. 18) apresenta o território como "objeto de relações simbólicas e é nele que os atores projetam suas concepções de mundo". As representações simbólicas e culturais de um território são expressas pelas territorialidades, um retrato da produção do mundo vivido, dos espaços do cotidiano, de relações de alteridade entre o "eu e o outro" e de pertencimento. Ousamos considerar ainda que as territorialidades, por esse modo de ver, expressam o sentido de ser-no-mundo.

$\mathrm{Da}$ escolha metodológica e das bases teóricas, elegeu-se como instrumentais de investigação o levantamento bibliográfico, a pesquisa de campo com observação dirigida, o diário/caderneta de campo e a entrevista semiestruturada cujo roteiro foi norteado pela compreensão dos modos de vida dos sujeitos em que pese o registro de seus saberes e seus fazeres na linha do tempo, envolvendo tanto elementos de cunho material quanto simbólico e perceptivo.

Pela linha do tempo e pelo registro dos saberes e fazeres das gentes do Baixo São Francisco, apreendemos as características que lhes confere singularidade e os elementos que dinamizam a vida no rio, entrecruzando historicidade e geograficidade. Essa construção permeou as transformações ocorridas no rio e no sertão nas últimas décadas, principalmente após a construção das grandes barragens e da transformação da caatinga em extensas manchas de pastagem. 


\section{O rio São Francisco (re)visitado: mudanças e permanências}

Concordamos com Cruz (2007, p. 260) ao considerar a identidade como fruto de "uma construção histórica e relacional dos significados sociais e culturais que norteiam o processo de distinção e identificação de um indivíduo ou de um grupo". Essa construção nos remete à ideia de mudanças e permanências, ou seja, a construção da identidade enquanto multiplicidade e movimento em diferentes tempos e espaços, em diferentes contextos socioculturais.

A identidade enquanto construção histórica já fora apontada por Hall (2004, p.111), para quem a identidade está sempre sujeita à ressignificação, evolvendo os vínculos de pertencimento, as heranças e as aspirações futuras. Essa concepção nos permite importante aproximação para discutir o pertencimento e a identidade envolvendo, simultaneamente, as transformações pelas quais o rio São Francisco e os povos que, historicamente, ocupam suas margens têm sofrido em decorrência, primeiro, dos ciclos econômicos e, segundo, dos grandes projetos de desenvolvimento nacional, a saber, a construção das usinas hidroelétricas no curso do rio, sobretudo nos anos subsequentes à década de 1950.

Em ordem cronológica, a primeira usina construída no rio São Francisco e a entrar em operação foi a usina Paulo Afonso I, no ano de 1955; em seguida, Três Marias, em 1963; Paulo Afonso II, no ano de 1965; e Paulo Afonso III, em 1968. No período subsequente, houve a inauguração da usina Apolônio Sales (Moxotó) e Sobradinho, ambas entraram em operação em 1978; Paulo Afonso IV, em 1980; Itaparica e Xingó, nos anos de 1988 e 1994, respectivamente.

Vargas (1999), Fontes (2011) e Pfau (2011) enfatizam as consequências políticas, geográficas e sociais dessas barragens e traduzem essas consequências pela leitura e apreensão de duas dimensões específicas: a dimensão que traduz um rio-território e a dimensão que expõe um rio-lugar.

O rio-território pode ser entendido como de caráter estratégico e marcado pelas táticas de ocupação, pela dimensão do poder territorial/econômico, associado diretamente ao processo de adensamento do colono e do gado para o interior de ocupação ainda incipiente (MONTEIRO, 2013), da busca por metais/pedras preciosos, da expropriação e da dominação das populações nativas que se adensavam ao longo do vale e, por último, não menos importante, pelo transporte de mercadorias e passageiros por entre as águas. Trata-se de um rio de usos múltiplos em detrimento da exploração econômica e de interesses unilaterais, sem o devido 
atentamento às necessidades e à condição de vida particular dos povos locais. $O$ rio da "integração nacional", de drenagem perene, de controle e ocupação do território era, no imaginário e na práxis, também, o rio das possibilidades.

Assim, por suas potencialidades, o planejamento do desenvolvimento do vale do São Francisco, seja no aproveitamento do potencial energético, seja no aproveitamento dos recursos de solo e água para fins agrícolas, inseriu-se, a parir da década de 1940, no contexto do desenvolvimento nacional e regional. (VARGAS, 1999, p. 89).

A inserção da técnica no processo de desnaturalização das paisagens sanfranciscanas, principalmente com as barragens, e a consequente alteração no curso das águas tornou esse rio de possibilidades em um rio de limites. Esses limites são físicos, a exemplo das alterações no canal fluvial, da construção das barragens e lagos, que provoca a diminuição da vazão natural do rio, a inundação de extensas áreas de terra, a transposição das águas, a degradação das terras marginais, a destruição das matas ciliares, etc. Mas, também, são fruto das representações expressas pelas gentes sanfranciscanas do antes e do após. Rio e homem (ribeirinhos) foram transformados, um em função do outro.

Pelas representações, torna-se possível apreender "toda a riqueza de valores que dão sentido aos lugares da vida dos homens e mulheres; pelas representações também é possível entender a maneira pela qual as pessoas modelam as paisagens e nelas afirmam suas convicções e suas esperanças". (ALMEIDA, 2018, p. 139).

No rio São Francisco, as transformações apresentadas como modernizadoras foram impostas pelos de fora e configuram aquilo que Andreotti (2006, p. 66) chamou de antipaisagem, implicando a desfiguração dos lugares "fruto de intervenções banais, incoerentes e desordenadas, desprovidas de identidade e de memória histórica".

Ao analisar o vale do rio São Francisco após as barragens, Pfau (2011, p. 78) considerou que essas "afundaram cidades, igrejas e sítios arqueológicos, desapropriaram índios, quilombolas e vazanteiros, mexeram nas tradições e cultura dos ribeirinhos". Acerca do baixo curso, Fontes (2011, p. 43) avalia que a "construção da barragem de Xingó representou o marco definitivo em relação ao controle do homem sobre o comportamento do seguimento do sistema fluvial situado à jusante dessa barragem".

Não é exagero afirmar que o fechamento da barragem para fins de enchimento do reservatório de Xingó selou de forma bastante 
simbólica, as condições ainda remanescentes do canal natural para o baixo curso do rio São Francisco. Naquele momento, pode-se dizer, em termos figurativos, que morria de forma simbólica o "Velho Chico" tal como presente no imaginário popular. (FONTES, 2011, p. 43).

O controle definitivo da vasão do rio pelas grandes barragens (Figura 2) influenciou de maneira significativa os modos de vida das populações ribeirinhas, que já não mais dispunham das enchentes periódicas que traziam fertilidade às várzeas e lagoas amplamente ocupadas pela cultura arroz. Ocorria, assim, o declínio de um modelo econômico singular, com alterações também no sistema de transporte fluvial, que passou a funcionar de maneira deficitária dada as condições de vasão e assoreamento causado pelo acúmulo de sedimentos.

\section{Figura 2 - Usina Hidroelétrica de Xingó, entre os estados de Alagoas e Sergipe}

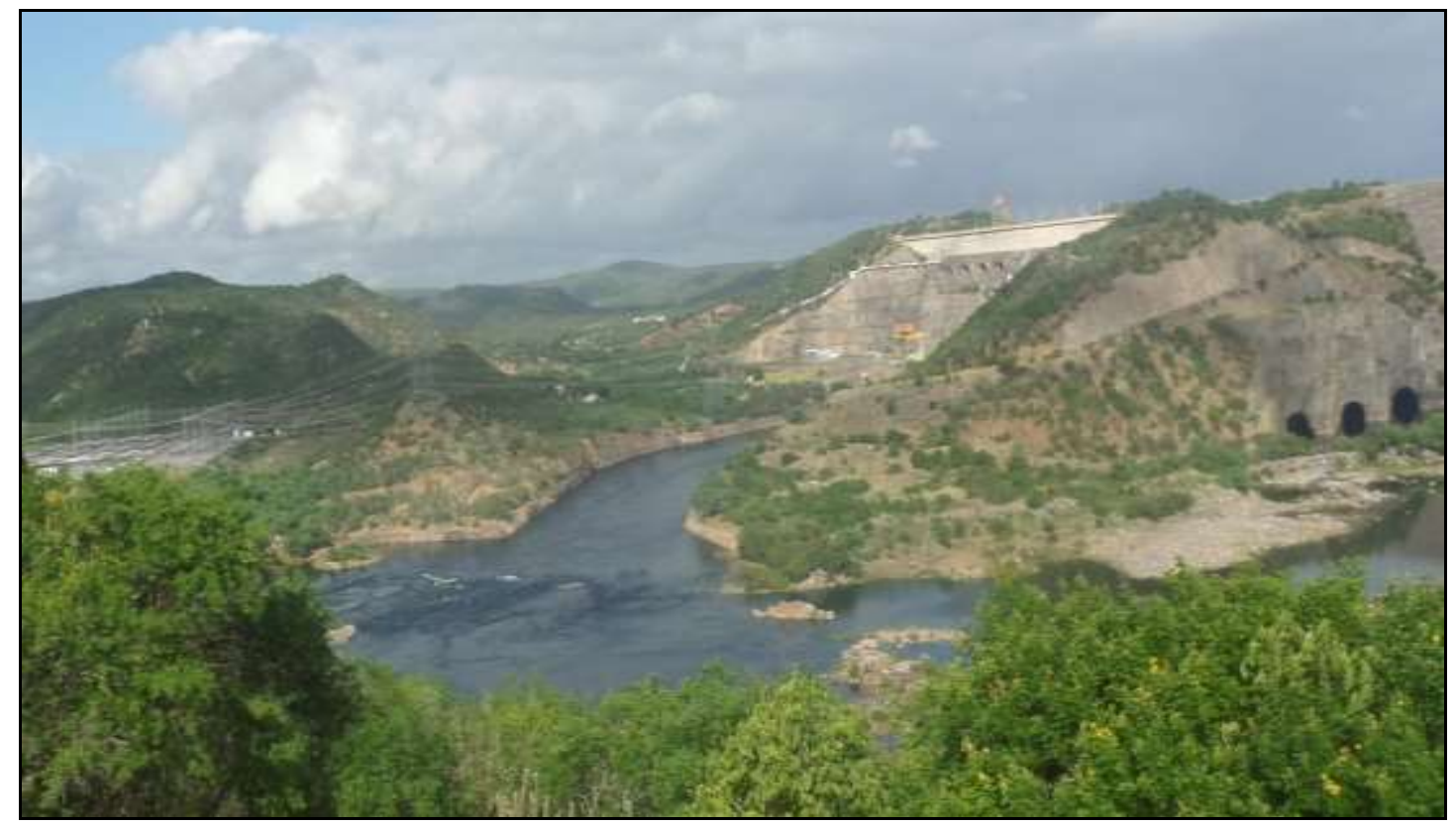

Fonte: Silva (2019).

O rio-lugar é marcado, sobretudo, pelas relações de pertencimento, de identidade, um mundo de significados organizados ou, como nos diz Tuan (2013), um microcosmos com pluralidade de sujeitos e de culturas entre as margens.

Uma cepa de gente, forjada a ferro e a fogo, resultante principalmente da mestiçagem do branco aventureiro com o indígena rebelde e em menor grau com o africano sedicioso (a rebeldia do escravo africano ao longo do São Francisco é bem representada pelas inúmeras comunidades quilombolas existentes ao longo do vale), amalgamada com a terra que pisava sofrida pelas secas periódicas. (CHAGAS, 2014, p. 38).

As relações de convivialidade caracterizam, pois, modos de vida próprios, formas de uso do rio, das águas e das terras (Figura 3) onde as referências 
materiais, simbólicas e míticas (lendas, contos, os seres que habitam as águas e as terras à beira rio) se confundem com a vida dos sujeitos e fazem parte de sua historicidade.

Figura 3: Relações de Convivialidade: lavagem de roupas no rio São Francisco, povoado de Cajueiro, município de Poço Redondo/SE

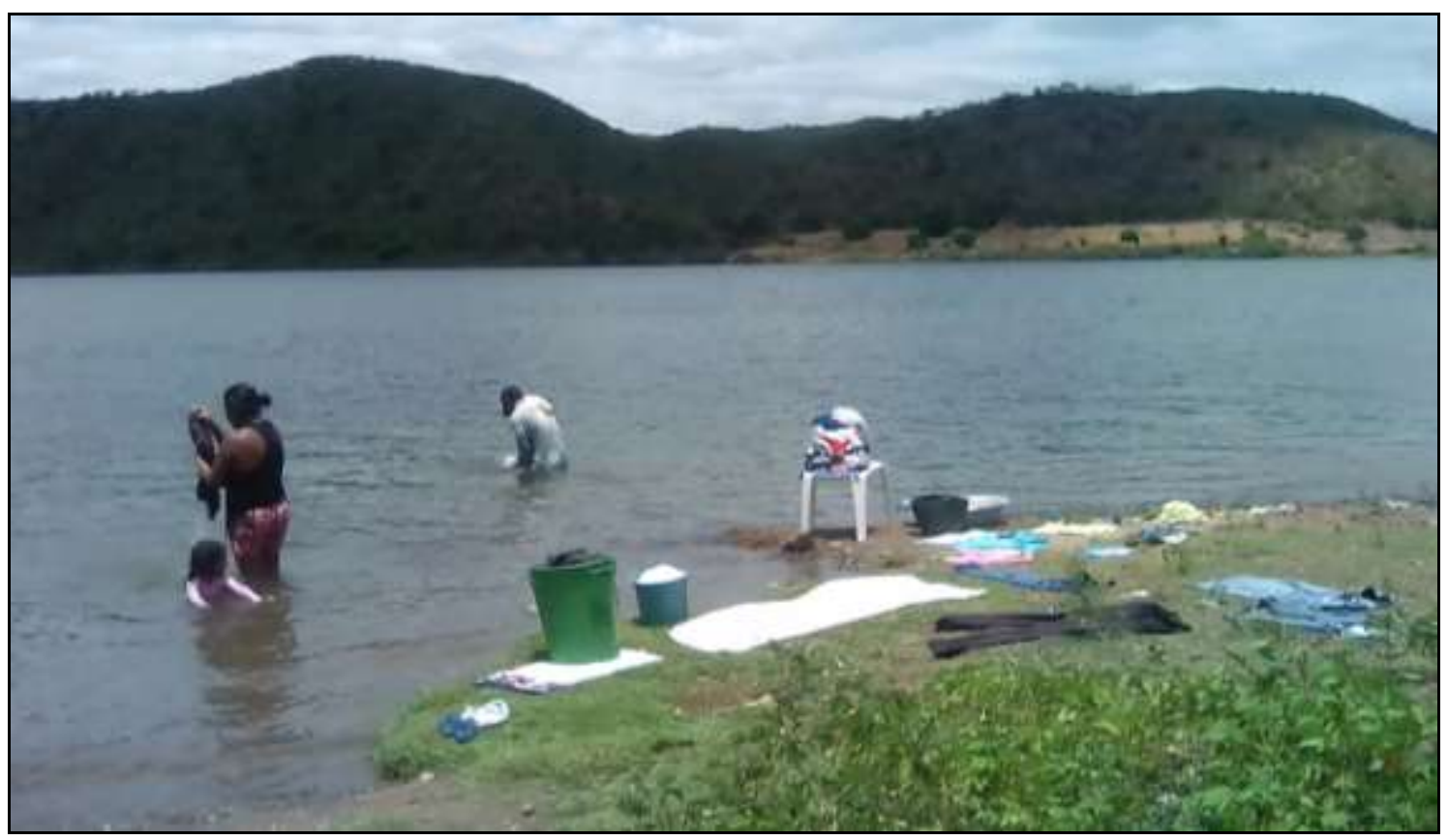

Fonte: Silva (2019).

Por essa dimensão, o rio é um lugar caracterizado por modos de ser, saber, fazer e sentir em diferentes escalas. A espacialidade geográfica do rio São Francisco e das terras adjacentes foi, paulatinamente, tomando sentido de lugar pelas experiências de vida e pelas práticas cotidianas. Assim, estamos em concordância que "o lugar abre a perspectiva para se pensar o viver e o habitar, o uso e o consumo, o processo de apropriação do espaço". (CARLOS, 2007, p. 14).

A autora considera ainda que o lugar pode ser analisado pela tríade habitanteidentidade-lugar e "guarda em si e não fora dele o seu significado e as dimensões do movimento da vida, possíveis de ser apreendido [sic] pela memória através dos sentidos do corpo". Lugar, então, é multiescalar, de dimensões difíceis de serem estabelecidas, onde constituímos valores, e onde nossas identidades se enraízam pelo material e pelo simbólico.

Ao apresentar o lugar enquanto constructo da memória e da identidade, Marandola Jr. (2014, p. 229) considera que:

O lugar não possui uma escala definida, nem uma temporalidade a priori dada. O tempo é vivido como memória, e por isso memória e identidade adensam o lugar. A memória é a experiência vivida que 0 
significa, definindo-o enquanto tal. Não é à toa que pensar o lugar é mais fácil recuando no tempo: lugar de nascimento, lugar de lembranças, lugar de saudade, lugar de memória, lugar de identidade. Ele [o lugar] parece mais conectado a uma tradição, a uma experiência profunda de entrelaçamento com a terra. Um ritmo lento onde o sentido da permanência prevalece.

O rio, pensado como lugar da vida, mesmo possuindo limites físicos bem estabelecidos (Figura 4), constitui, também, o lugar do intangível. "O intangível não é invisível, mas é de difícil apreensão. Como se avalia os danos provocados em uma cachoeira com a construção de uma barragem? Como se avalia a vista contemplativa de um pôr-do-sol?". (ALMEIDA, 2018, p. 25). Indagaríamos ainda: como avaliar os sentidos do rio e do sertão na construção do ser ribeirinho, e mais, de ser ribeirinho sertanejo?

\section{Figura 4 - Rio São Francisco entre os estados de Alagoas e Sergipe}

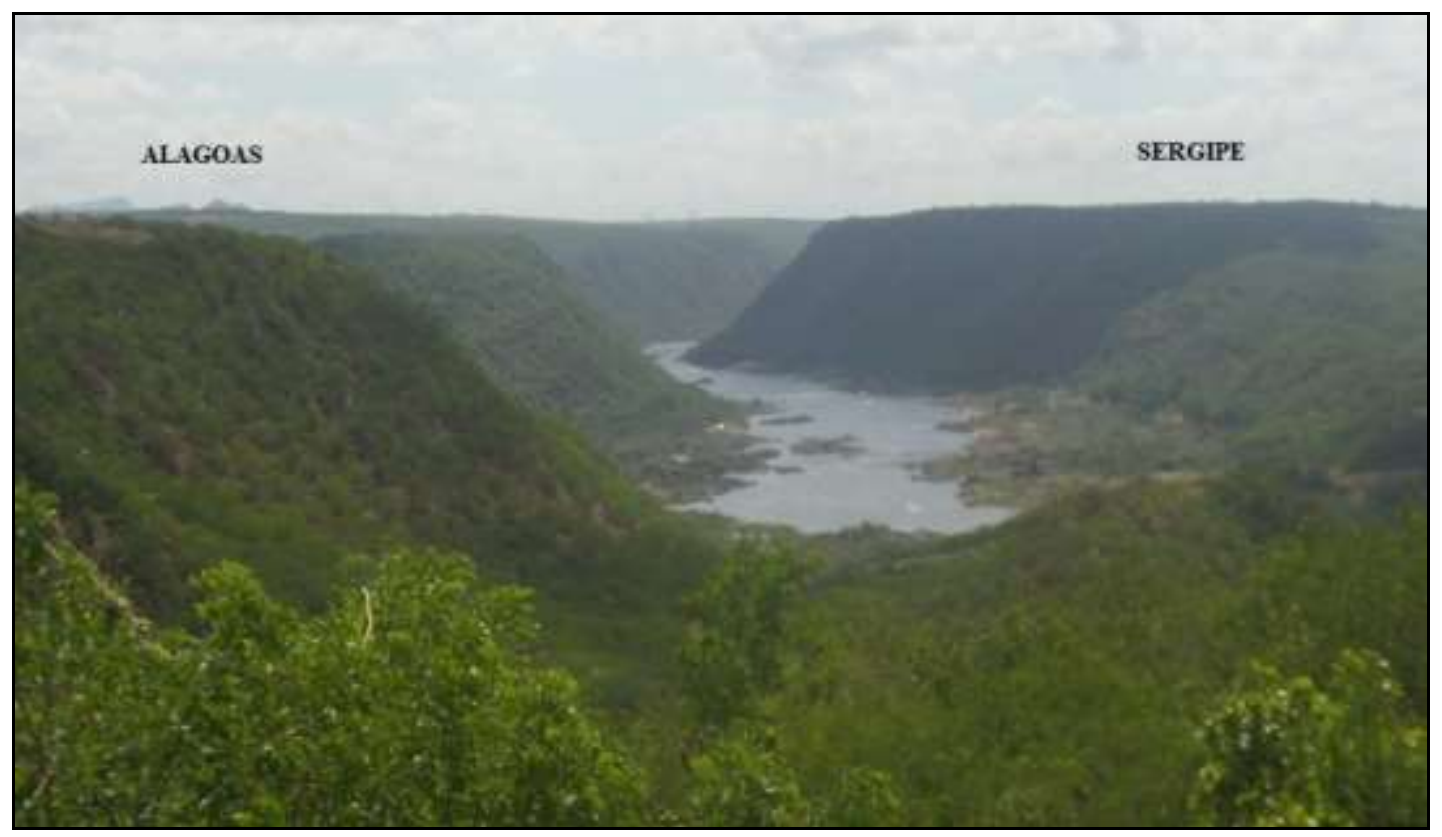

Fonte: Silva (2019).

Por essas indagações, passamos a considerar o rio São Francisco enquanto um lugar de valores que não podem ser aferidos. A mediação entre valor e significado faz-se pelas representações intersubjetivas expressas no cotidiano, pelas relações de convivialidade com o lugar/mundo vivido.

Para Almeida (2018, p. 142), "os lugares vividos são frutos das relações tecidas entre os homens e o meio e os sentimentos de pertencimento; sentimentos que correspondem às práticas e às aspirações, estando estas relações codificadas por signos que Ihes dão significados". Pelas dimensões culturais e de pertencimento, 
poderíamos considerar o rio São Francisco enquanto lugar vivido, como um rio de significados, de memórias, o lugar da existência e, por assim dizer, também de resistência.

\section{O que "faz" ser ribeirinho sertanejo?}

Pelas discussões até o momento apresentadas, pensamos ter construído as bases necessárias a se pensar os sentidos de ser ribeirinho sertanejo. Primeiro, é necessário considerar que, do ponto de vista geográfico, a tipologia apresentada como ribeirinho sertanejo enseja apresentar os sujeitos que se encontram no caminho das águas semiáridas. No caso da pesquisa, como amostra empírica, remetemo-nos àqueles que se localizam (residem ou trabalham) entre as margens semiáridas do Baixo rio São Francisco - Alagoas/Sergipe - e possuem relação direta com o rio.

Destarte, estamos em consonância com Almeida (2008, p. 318) ao considerar que "as identidades se imbricam, se mesclam e apresentam dinamicidade, o que não permitiria, também, referir-se a uma identidade cultural e territorial unívoca para o sertanejo". As identidades sertanejas são múltiplas, tanto quanto são múltiplos os sentidos de sertão e de sertanejo.

Sob o ponto de vista das representações e pela influência da natureza do lugar, as gentes que povoam o rural e o urbano às margens do rio São Francisco apresentam tipologias diversas. De modo geral, são apresentados como ribeirinhos: vazanteiros e/ou barranqueiros (ALMEIDA, 2008); caboclos, geraizeiros, veredeiros e chapadeiros (CUNHA e BORGES, 2013); ilheiros (SOUZA, 2012; 2018); beradeiros (expressão apreendida em entrevista no povoado Mocambo, Baixo São Francisco sergipano em outubro de 2018), indígenas, quilombolas, entre tantos outros. E aqui apresentamos, especificamente, os ribeirinhos sertanejos.

Todas essas tipologias apresentam como especificidade um conjunto de relações territoriais materializadas pelos usos e significados atribuídos à natureza do meio em que os ribeirinhos sertanejos habitam. Essas especificidades são reveladas pelas percepções, pelas crenças, pelos saberes e pelas potencialidades do ambiente e são traduzidas e ressignificadas no decurso "histórico-cultural", tal como apresentado por Vargas $(1999$, p. 25) ao discutir os vetores de 
desenvolvimento regional do Baixo São Francisco e sua influência na cultura e na transformação dos modos de vida ribeirinho.

Pela ressignificação, estamos de acordo com Hall (2004) ao considerar que a identidade está sempre em processo, em uma constante construção que envolve raízes e o sentido de ser, mas também as aspirações futuras, ou seja, "em quem nós podemos nos tornar". Nesse contexto, Cruz (2007, p. 261) considera que "as identidades, nunca são, portanto, completamente determinadas, unificadas, fixadas".

Castells (1999, p. 22) atem-se à identidade enquanto "o processo de construção de significados com base em um atributo cultural, ou ainda em um conjunto de atributos culturais inter-relacionados, o(s) qual(ais) prevalece $(\mathrm{m})$ sobre outras fontes de significados". Por cultura, compreendemos, aportados em Claval (2002, p. 228), "a soma de comportamentos, dos saberes, das técnicas, dos conhecimentos e dos valores acumulados pelos indivíduos durante suas vidas". Assim, identidade e cultura têm a ver com experiências, vivências e com os sentidos de ser, pertencer e sentir.

O sentido de ser ribeirinho se dá pelo rio. O sentido de ser ribeirinho sertanejo está associado ao rio, mas também ao domínio das terras semiáridas delimitadas natural e politicamente. O sentido de sertão, pela exposição dialógica dos sujeitos na pesquisa, associa-se tanto ao domínio morfoclimático das caatingas, quanto às representações subjetivas inerentes a esses.

Em algumas falas (relatos), o sentido de ser sertanejo ultrapassa os limites do ambiente físico - embora aqui tenhamos nos restringido ao semiárido do Baixo São Francisco -, e tem como referência o outro que chega, ou seja, os de fora. Essa conotação é apresentada por Almeida (2018, p. 143) ao considerar que "o sertão passou a ter uma representação cultural e ideológica que reforça o distanciamento entre o eu e o outro".

"Aqui é sertão, quem sobe o rio diz que tá subindo pro sertão" (agricultora, 54 anos, povoado Mocambo/SE, outubro de 2018). Essa narrativa expressa por uma moradora do povoado Mocambo, na margem sergipana do rio São Francisco, traznos a demonstração de que "subir o rio" é ir pro sertão. Nesse caso, em específico, referiu-se àqueles que saem de Propriá/SE e Porto Real do Colégio/AL, em direção a Pão de Açúcar (margem alagoana, a montante de Porto Real do Colégio) e ao povoado Mocambo (margem sergipana, a montante de Propriá).

O ser sertanejo, pelo exposto, também faz alusão às dificuldades da vida cotidiana e as histórias de vida. "Sou sertanejo sofredor, porque todo sertanejo é 
sofredor" (pescador/agricultor, 47 anos, povoado Niterói/SE, outubro de 2018). Em outros termos, a ideia de sertão é expressa, também, pela ideia de subalternidade em relação a outros sujeitos e/ou lugares. O fato de "ser sofredor" daria sentido ao ser sertanejo e, desse modo, não teríamos uma base tangível que caracterizasse o espaço sertão, já que esse constitui uma representação subjetiva, um estado social/emocional e, pela narrativa, caracterizaria o sertão representado por Guimarães Rosa (1986, p. 17): "Sertão. Sabe o senhor: sertão é onde o pensamento da gente se forma mais forte que o poder do lugar".

Ao tecer do diálogo, chama-se a atenção para o fato de que o "ser sofredor" se desvela pelas dificuldades enfrentadas no cotidiano com ênfase ao fenômeno natural da seca, agravado pela improdutividade das terras fortemente antropizadas e pela degradação do rio. Por esse delineamento, o sertão não está dissociado de uma base material. É físico, palpável e sentido. "Aqui é o sertão bravo, de terra seca, ninguém planta nada" (pescador, 42 anos, povoado Niterói/SE, outubro de 2018). "A gente vive na beira do rio, mas aqui é sertão, o rio é uma riqueza. Sou ribeirinho, mas sou sertanejo, passei a vida aqui no sertão" (agricultor/pescador, 58 anos, povoado Curralinhos/SE, janeiro de 2019).

Para Vargas (2003, p. 113), "adentrar no Baixo São Francisco é, antes de tudo, apreender a cultura sertaneja e suas relações com a base física de sustentação e seus respectivos níveis tecnológicos". Em continuidade, endossa que "o significado de ser ribeirinho e sertanejo pode vir a ser encabeçado por um processo de ressignificação de sua cultura". (VARGAS, 2003, p.130).

O papel da natureza como base à construção da identidade do ribeirinho sertanejo é apresentado pelo vivido e pelas relações de convivialidade entre homem, rio e sertão semiárido. "Com a seca, ninguém planta nada, só se for com a água do rio". "Sou ribeirinha porque vivo aqui, Pão de Açúcar [cidade localizada na margem alagoana] está na beira do rio, é uma cidade ribeirinha, mas está no sertão, aqui é alto sertão, então eu sou sertaneja, sou ribeirinha e sertaneja" (professora, 53 anos, Pão de Açúcar/AL, outubro de 2018).

A construção do lugar-território pelos ribeirinhos sertanejos e pelas gentes do rio São Francisco se dá pelo modo particular pelo qual o espaço local é produzido e organizado e pelas significações atribuídas a ele. Pertencer ao rio e ao sertão é mais do que estar em um lugar setorizado, estanque. Rio e sertão são os lugares da existência, do enraizamento e onde são atribuídos valores e significações tanto pelo 
material quanto pelos símbolos inerentes às representações individuais e coletivas dos diferentes sujeitos.

Os ribeirinhos sertanejos, pelo olhar de quem o é, não pertencem aos povoados e demais localidades que margeiam o rio São Francisco. Eles, pelas experiências cotidianas, relações de convivialidade e pelas representações simbólicas, pertencem a um lugar maior - o rio, que é moldado pelo sertão de sentidos, significados e dimensões ambivalentes, transformando o caminho das águas semiáridas no lugar da existência e do enraizamento. "Aqui o Sertão chega no rio, viver aqui é uma riqueza" (barqueiro/pescador, 44 anos, comunidade Rabelo/AL, janeiro de 2019).

O pertencimento ao rio e ao sertão não apresenta unicidade, difere entre os sujeitos, povoados e sedes de município. Os usos da terra e das águas caracterizam esse pertencimento, ora "estreita-se" com o rio (muito evidente no povoado Niterói, margem sergipana e na cidade de Pão de Açúcar, margem alagoana), ora com o sertão (averiguado no Povoado Mocambo, margem sergipana).

Pela linha do tempo são reportadas sempre as histórias de vida e, pelo exercício da memória, são evidenciadas as lembranças de experiências vividas no ambiente sanfranciscano. Ser ribeirinho sertanejo é, entre tantos outros elementos, conviver com as lembranças dos tempos de "fartura" no sertão, as lembranças dos roçados de algodão, de milho, mandioca, da produção de corda com fibra do Sisal. Ser ribeirinho sertanejo é lembrar-se da última cheia do rio na década de 1990, do plantio nas várzeas arrozeiras e do vapor, das fragatas e das canoas de tolda (tipos de embarcações) que navegavam naquelas águas.

\section{Tecendo conjecturas: considerações finais}

A construção do lugar perpassa pelas experiências e pelas vivências que cotidianamente desenvolvemos em determinada realidade. Essa construção é processual, ou seja, no tempo-espaço, está sujeita a ressignificações caracterizadas por processos de mudanças e permanências mediados de valores e significados diversos. Assim está caracterizada a realidade geográfica do Baixo São Francisco.

Entre terras e águas as gentes sanfranciscanas desenvolvem suas vidas, talhadas em um ambiente físico, como também moldado por culturas e relações de pertencimento afetivas e identitárias. Enquanto território, o rio é espaço de disputas, conflitos, poder e, ainda, de identidade. É um ambiente estratégico de nuances diversas. Como lugar, o rio é base existencial, é suporte da vida e do 
sentido de ser-no-mundo. É o espaço onde as necessidades básicas são satisfeitas.

Viver e pertencer ao lugar-território sanfranciscano é, também, um exercício de memória, de lembranças. Lembranças das enchentes, das vazantes, do arroz e do algodão. Essas lembranças caracterizam os modos de ser das gentes do rio, em suas diversas identidades territoriais, que rotineiramente expressam a angustia de tempos que não voltam, das "farturas" e da bonança.

Entre as margens semiáridas, aqui expressas como objeto de representação empírica, rio e sertão se integram se entrelaçam e formam o amálgama de ser ribeirinho, mas também de ser sertanejo. "Sou ribeirinho no sertão" (pescador/agricultor, 58 anos, povoado Ilha do Ferro/AL, janeiro de 2019). Entre o rio e o sertão coexistem gentes de realidades diversas, moradores de povoados, fazendas, sedes de municípios, etc. Portanto, essas gentes apenas habitam essas localidades pontuais, porque a vida passa "mais nas águas do que em casa" (pescador, 55 anos, Canindé de São Francisco/SE, janeiro de 2019).

Rio e sertão moldam o sentido de ser ribeirinho sertanejo, em que "os ciclos da terra e das águas formam o cenário dos sujeitos do campo e da cidade". (PAULA, 2012, p. 74). Não há, desse modo, como pensar o Baixo São Francisco e suas gentes sem aferir o sentido do sertão. Sertão de territorialidades e de gentes com identidades plurais, diversas.

A respeito das identidades territoriais reafirmamos a ideia de que essas são múltiplas e se expressam pelas representações e pelos significados atribuídos às vivências e práticas cotidianas. São relações simbólicas e afetivas marcadas, sobremaneira, pela convivialidade com a natureza, ou seja, com um rio que é lugar e território. Modos de vida próprios ressignificados pelo uso da técnica e pela transformação das paisagens ribeirinhas caracterizam - bem como são caracterizados por - novos sentidos de ser e estar, de ser ribeirinho, sertanejo e ribeirinho sertanejo no lugar-território sanfranciscano.

\section{Referências}

AB' SABER, Aziz Nacib. Sertões e Sertanejos: uma geografia humana sofrida. In: Estudos Avançados. Dossiê Nordeste Seco, São Paulo: Centro de Estudos Avançados, v. 13, n. 36, 1999.

ALMEIDA, Maria Geralda de. Geografia Cultural: um modo de ver. Goiânia: Gráfica UFG, 2018. 
ALMEIDA, Maria Geralda de. Etnogeografia do Brasil Sertanejo. In: SERPA, Ângelo (Org.). Espaços culturais: vivências, imaginações e representações [online]. Salvador: EDUFBA, 2008.

ALMEIDA, Maria Geralda de. Fronteiras, Territórios e Territorialidades. Revista da ANPEGE, N.2. 2005, p.103-114.

ANDREOTTI, Giuliana. "Anti-paesaggio”. In CAMPIONE, C.; FARINELLI, F.; SANTORO, C. (Orgs.) Scritti per Alberto Di Blasi. Bologna: Pàtron, 2006.

BRANDÃO, Carlos Rodrigues. Olhares Cruzados Sobre um Rio e Suas Gentes. In: LEAL, Alessandra Foneca; BORGES, Mariestela Corrêa (Orgs.). Etnocartografias do Rio São Francisco: comunidades tradicionais ribeirinhas do Norte de Minas Gerais. Uberlândia: EDUFU, 2013.

CARLOS, Ana Fani Alesssandri. O Lugar no/do Mundo. São Paulo: Hucitec, 2007. CHAGAS, Ivo das. Eu Sou o Rio São Francisco. Montes Claros - MG: Ed Unimontes, 2014.

CASTELLS, Manuel. O Poder da Identidade. São Paulo: Paz e Terra, 1999.

CLAVAL, Paul. A Volta do Cultural na Geografia. Mercator, ano 1, n¹, 2002.

CRUZ, Valter do Carmo. Itinerários Teóricos Sobre a Relação Entre Território e Identidade. In: BEZERRA, Amélia Cristina Alves; ARRAIS, Tadeu Alencar. (Orgs.). Itinerários Geográficos. Niterói: EdUFF, 2007.

CUNHA, Maria das Graças Campolina; BORGES, Maristela Corrêa. Cultivando Culturas Populares: os arranjos e rearranjos dos grupos de cultura popular com estratégia de re-existência. In: LEAL, Alessandra Foneca; BORGES, Mariestela Corrêa (Orgs.). Etnocartografias do Rio São Francisco: comunidades tradicionais ribeirinhas do Norte de Minas Gerais. Uberlândia: EDUFU, 2013.

DARDEL, Eric. O Homem e a Terra: a natureza da realidade geográfica. São Paulo: Perspectiva, 2015.

FONTES, Luiz Carlos da Silveira. O Rio São Francisco Após as Grandes Barragens. In: LUCAS, Ariovaldo Antonio Tadeu; AGUIAR NETTO, Antenor de Oliveira (Orgs.). Águas do São Francisco. São Cristóvão - SE: UFS, 2011.

HALL, Stuart. Identidade Cultural na Pós-Modernidade. 11ํㅡㄹ ed. Rio de Janeiro: Imprensa do Brasil, 2004.

HAESBAERT, Rogério. As Armadilhas do Território. In: SILVA, José Borzacchiello da; SILVA, Cícero Nílton Moreira da; DANTAS, Eustógio Wanderley Correia (Orgs.). Território: modo de pensar e usar. Fortaleza: Edições UFC, 2016.

MARANDOLA JR., Eduardo. Lugar Enquanto Circusntancialidade. In: HOLZER, Werther; OLIVEIRA, Lívia de (Orgs.). Qual o Espaço do Lugar?. São Paulo: Perspectiva, 2014.

MENDES, Jeisa Flores; ALMEIDA, Maria Geralda de. Identidade, Lugar e Território nas Representações do Sertão da Ressaca - Bahia. Geonordeste, ano XX, n.1, 2009.

MERLEAU-PONTY, Maurice. Fenomenologia da Percepção. São Paulo: Martins Fontes, 1996.

MONTEIRO, Carlos Augusto de Figueiredo. Depoimentos Reflexivos: sobre a produção de um geógrafo brasileiro da segunda metade do século XX. Arapiraca AL: EdUneal, 2013. 
MORAES, Antonio Carlos Robert. O Sertão: um "outro" geográfico. Terra Brasilis, Rio de Janeiro, anos iii - iv, n. 4-5, 2002-2003.

NOGUEIRA, Amélia Regina Batista. Uma Interpretação Fenomenológica na Geografia. In: X Encontro de Geógrafos da América Latina. Anais. São Paulo: EGAL, 2005.

OLIVEIRA, Lívia de. Ainda Sobre Percepção, Cognição e Representação em Geografia. In: MENDOÇA, Francisco; KOZEL, Salete. (org.). Elementos de Epistemologia de Geografia Contemporânea. Curitiba: Ed. Da UFPR, 2002.

PAULA, Andréa Maria Narciso Rocha de. O Sertão é Uma Espera Enorme: a comunidade da Barra do Pacuí. In: COSTA, João Batista de Almeida; OLIVEIRA, Cláudia Luz de (Orgs.). Cerrado, Gerais, Sertão: comunidades tradicionais nos sertões roseanos. São Paulo: Intermeios, 2012.

PFAU, Luisa. Viagem Pelas Margens do Rio São Francisco. In: LUCAS, Ariovaldo Antonio Tadeu; AGUIAR NETTO, Antenor de Oliveira (Orgs.). Águas do São Francisco. São Cristóvão - SE: UFS, 2011.

PIERSOM, Donald. O Homem no Vale do São Francisco. Rio de Janeiro: SUVALE, 1972. Tomo I.

ROSA, Guimarães. Grande Sertão: veredas. 20ํㅡㄹ ed. Rio de Janeiro: Nova Fronteira, 1986.

SOUZA, Ângela Fagna Gomes de. A Paisagem Sanfranciscana: nuances e cenários de ontem e de hoje. Revista da Ampege, n. 23, v. 14, 2018, p. 80-119.

SOUZA, Ângela Fagna. Ciclos de vida nos lugares das águas: as ilhas do rio São Francisco em Pirapora/MG. In: João Batista de Almeida Costa; Claudia Luz de Oliveira. (Org.). Cerrado, Gerais, Sertão: comunidades tradicionais nos sertões roseanos. São Paulo: Intermeios, 2012.

SOUZA, Ângela Fagna; BRANDÃO, Carlos Rodrigues. Paisagem, Identidade e Cultura Sanfranciscana: sujeitos e lugares das comunidades tradicionais localizadas no entorno e nas ilhas do médio rio São Francisco. Geo UERJ, n. 23, v.2, 2012, p. 01-13.

SOUZA, Marcelo Lopes de. Os Conceitos Fundamentais da Pesquisa Sócioespacial. Rio de Janeiro: Bertrand Brasil, 2013.

TUAN, Yi-Fu. Espaço e Lugar: a perspectiva da experiência. Londrina: Eduel, 2013.

VARGAS, Maria Augusta Mundim. Sustentabilidade Cultural e as Estratégias de Desenvolvimento do Baixo São Francisco. In: ALMEIDA, Maria Geralda; RATTS, Alecsandro JP. (Orgs.). Geografia: leituras culturais. Goiânia: Alternativa, 2003.

VARGAS, Maria Augusta Mundim. Desenvolvimento Regional em Questão: o Baixo São Francisco revisitado. São Cristóvão - SE: UFS, 1999 


\section{NOTAS DE AUTOR}

\section{CONTRIBUIÇÃO DE AUTORIA}

Cícero Bezerra da Silva - Concepção. Coleta de dados, Análise de dados, Elaboração do manuscrito, revisão e aprovação da versão final do trabalho

Maria Augusta Mundim Vargas - Concepção e elaboração do manuscrito. Coleta de dados Participação ativa da discussão dos resultados; Revisão e aprovação da versão final do trabalho.

\section{FINANCIAMENTO}

Concessão de bolsa de mestrado pelo Conselho Nacional de Desenvolvimento Científico e Tecnológico (CNPq). Trabalhos de campo desenvolvido com o apoio integral da Universidade Federal de Sergipe.

\section{CONSENTIMENTO DE USO DE IMAGEM}

Não se aplica

\section{APROVAÇÃO DE COMITÊ DE ÉTICA EM PESQUISA}

Não se aplica.

\section{CONFLITO DE INTERESSES}

Não se aplica.

\section{LICENÇA DE USO}

Este artigo está licenciado sob a Licença Creative Commons CC-BY. Com essa licença você pode compartilhar, adaptar, criar para qualquer fim, desde que atribua a autoria da obra.

\section{HISTÓRICO}

Recebido em: 17-06-2019

Aprovado em: 12-12-2019 